\title{
Beyond the Tipping Point: Understanding Perceptions of Abrupt Climate Change and Their Implications
}

\author{
RoB BELLAMY \\ School of Environmental Sciences, and Tyndall Centre for Climate Change Research, University of East Anglia, \\ Norwich, United Kingdom \\ Mike Hulme \\ School of Environmental Sciences, University of East Anglia, Norwich, United Kingdom
}

(Manuscript received 8 June 2010, in final form 2 February 2011)

\begin{abstract}
This article explores the influence of personal values and ontological beliefs on people's perceptions of possible abrupt changes in the Earth's climate system and on their climate change mitigation preferences. The authors focus on four key areas of risk perception: concern about abrupt climate change as distinct to climate change in general, the likelihood of abrupt climate changes, fears of abrupt climate changes, and preferences in how to mitigate abrupt climate changes. Using cultural theory as an interpretative framework, a multimethodological approach was adopted in exploring these areas: 287 respondents at the University of East Anglia (UK) completed a three-part quantitative questionnaire, with 15 returning to participate in qualitative focus groups to discuss the issues raised in more depth. Supporting the predictions of cultural theory, egalitarians' values and beliefs were consistently associated with heightened perceptions of the risks posed by abrupt climate change. Yet many believed abrupt climate change to be capricious, irrespective of their psychometrically attributed worldviews or "ways of life." Mitigation preferences-across all ways of life-were consistent with the "hegemonic myth" dominating climate policy, with many advocating conventional regulatory or market-based approaches. Moreover, a strong fatalistic narrative emerged from within abrupt climate change discourses, with frequent referrals to helplessness, societal collapse, and catastrophe.
\end{abstract}

\section{Abrupt climate change in science and society}

The idea that changes in the Earth's climate system can be abrupt is not new. This way of thinking arguably emerged after 1963 when mathematician and meteorologist Edward Lorenz published his famous research paper "Deterministic Nonperiodic Flow" (Lorenz 1963). His publication provided a mathematical demonstration of how small changes in weather conditions could trigger abrupt meteorological consequences-a demonstration of nonlinear atmospheric behavior. When he plotted his findings in phase space they resembled the wings of a butterfly, an iconic visualization from which the powerful "butterfly effect" metaphor would later be derived.

Corresponding author address: R. Bellamy, School of Environmental Sciences, University of East Anglia, Norwich NR4 7TJ, United Kingdom.

E-mail: r.bellamy@uea.ac.uk
In 1966, three years after Lorenz's insight into the nonlinearity of weather, the first real-world evidence of abrupt changes in the Earth's climatic history were unearthed in Greenland (National Oceanic and Atmospheric Administration 2009). Analysis of the first ice cores to be drilled to bedrock challenged the long-held belief that changes in climate occurred gradually over thousands of years, showing past climates to have changed substantially over centennial or even decadal time scales (e.g., Dansgaard et al. 1969). However, it was not until 1987 that this historical evidence was formally connected to the possibility of future abrupt changes in climate. In his 1987 Nature commentary "Unpleasant Surprises in the Greenhouse?," Wallace Broecker introduced the idea that future climate changes would largely come as sudden surprises, comparing anthropogenic influences on climate to playing Russian roulette (Broecker 1987).

The idea of abrupt climate change has since evolved to become as much, if not more, of a social phenomenon than it has a scientific one. Questions about abrupt 
climate change are motivated not only by scientific curiosity, but by social, political, ethical, and cultural concerns about their potential impacts and how to mitigate them. The possibility of abrupt climate change therefore presents a new challenge for decision-making, forcing humanity to explore their ontological beliefs about the benign stability of the planet and their personal values-or "ways of life"-in a setting simultaneously characterized by great uncertainty and potential danger. Surprisingly, however, very little is known about how the risks of abrupt climate change-as distinct to the risks of climate change in general-are perceived (Lowe et al. 2006). In this article, we explore the influence of individual values and beliefs on perceptions of abrupt climate change, and on their preferences for the mitigation of such changes.

Recognizing the dominant role of values and beliefs in the social construction of risks, cultural theory (Douglas 1970; Thompson et al. 1990) has yielded valuable insights into perceptions of climate change in general (e.g., Leiserowitz 2005, 2006). Accordingly, exploring the value of cultural theory for understanding perceptions of abrupt climate change is not without promise, and it has therefore been used and evaluated in this study. In doing so, we focus on four key areas of risk perception: concern about abrupt climate change as distinct to climate change in general; the likelihood of abrupt climate changes; fears of abrupt climate changes; and preferences in how to mitigate abrupt climate changes.

\section{Understanding and communicating abrupt climate change}

\section{a. The nature of nonlinearity}

To understand the scientific basis of abrupt climate change we must return to the architect of the butterfly effect: Edward Lorenz. Upon publishing "Deterministic Nonperiodic Flow," he inadvertently became one of the early pioneers of what is today known as "Complexity Theory;" a theory rooted in understanding nonlinear "complex dynamical systems" such as the Earth's climate (Lewin 1999). Popularized in public discourse as "Chaos Theory" by James Gleick in 1988, Complexity Theory describes such systems as complex "emergent global structures," which arise from numerous simple interactions between the systems component parts.

Complex systems will often display "attractors," which are particular stable states to which they are drawn. If these systems are perturbed sufficiently, they may be knocked into alternate "stable states." Described by mathematicians as "strange attractors," these alternate states display internal dynamics that are qualitatively different from those of the previous state (Gleick 1988).
The critical threshold at which a system will inescapably fall into one of these strange attractors is called the bifurcation point, or, as it is now often popularly referred to in climate change discourses, the "tipping point" (see Russill and Nyssa 2009).

The nonlinearity of the Earth's climate system suggests not only that changes may be abrupt, but also that there are significant challenges in prognosticating future system behavior (e.g., Clark et al. 2002). Uncertainty continues to amass when we consider the nonlinear nature of the potentially impacted entities, such as human society and nonhuman ecologies. For the few who have engaged with the issue, this uncertainty built upon uncertainty has inevitably resulted in broad and largely speculative impact predictions, as argued by Hulme (2003).

\section{b. A climate of fear}

The different ways in which the uncertain science and speculative impacts of abrupt climate changes are interpreted inevitably extends to the ways in which they and the risks they pose are communicated across societies. Such uncertainty is frequently deployed in climate change debates, as an argument both for and against the implementation of earlier and more robust mitigation and adaptation strategies (e.g., compare Nordhaus 2007 with Spash 2007). Advocates of earlier action argue that these changes present an imminent and dangerous threat to humanity, while opponents argue the unknowns are too great to justify allocating resources.

Uncertainty also presents opportunities for abrupt climate change to be framed using different linguistic repertoires to engage with different audiences and service different purposes and agendas (Segnit and Ereaut 2007; Nisbet 2009). In abrupt climate change discourses, one of the most popular repertoires is that of "alarmism," which is often used in conjunction with the catastrophe frame. With the aim of engaging people's anxiety about the future, the system of language used within this repertoire is dominated by apocalyptic rhetoric, comprising words such as the increasingly popular "catastrophic."

Apocalyptic rhetoric is now frequently used in conjunction with the tipping point metaphor thereby revealing subjective and value-laden perceptions of risk. The media, politicians, and scientists can all adopt this stance, having used the metaphor in conjunction with "catastrophic" (former UK Prime Minister Tony Blair, in Laitner and Parker 2006); "points of no return" (Connor 2009); "inescapable apocalypse" (Phillips 2009) and "precipice... beyond which there is no redemption" (Hansen 2005).

Some have argued that constructing this apocalyptic vision of the future gives rise to an implicit sense of helplessness and fatalism (Hulme 2009a; Skrimshire 2011). On the other hand, others argue that the use of 
apocalyptic rhetoric is not alarmist but "alarming," in the sense that it is consistent with scientific evidence (Risbey 2008). Nevertheless, research has shown that efforts to induce behavior change through fear appeals are frequently counterproductive (O'Neill and NicholsonCole 2009; Moser 2010).

\section{Risk perception and cultural theory}

\section{a. Stability and mobility}

Cultural theory examines how shared values and beliefs-cultural biases-interact with interpersonal social relations to construct viable worldviews, or ways of life (Douglas 1970; Thompson et al. 1990). The need for congruence between cultural biases and social relations to construct viable ways of life has led to the development of the so-called impossibility theorem. This theorem argues that only five ways of life fulfill this prerequisite and are labeled "hierarchism," "individualism," "egalitarianism," "fatalism," and "autonomy."

The four primary ways of life can be mapped upon a "grid-group" typology, which captures an individual's involvement in social life via the two dimensions of "grid" and "group" (excluding autonomy, which holds attributes of withdrawal from social life altogether) (Douglas 1970). Grid denotes the extent to which an individual's life is prescribed by social regulation, while group denotes the extent to which an individual's life comprises social contact (see Fig. 1). These ways of life, it is argued, provide a valuable insight into why different people and cultures perceive risks differently (Thompson et al. 1990).

The stability of these ways of life is disputed among cultural theorists. Two interpretations exist, those of "stability" and "mobility." Proponents of stability claim that individuals seek to reproduce the same way of life in all social contexts (Rayner 1992). On the other hand, proponents of mobility claim that individuals may move between different ways of life in different contexts. Indeed, as one critic has put it "subjects may even change their way of life during the course of an interview or the task of filling out a questionnaire" (Boholm 1996).

\section{b. The myths of nature}

Cultural theory also argues that perceptions of nature are socially constructed via the ways of life. The four primary ways of life can be mapped onto corresponding ways of regarding nature, known as the "myths of nature:" perverse/tolerant, benign, ephemeral, or capricious (Holling 1986; Thompson et al. 1990). Each of the myths reveals a different way of viewing the stability or otherwise of the natural world (see Fig. 2).

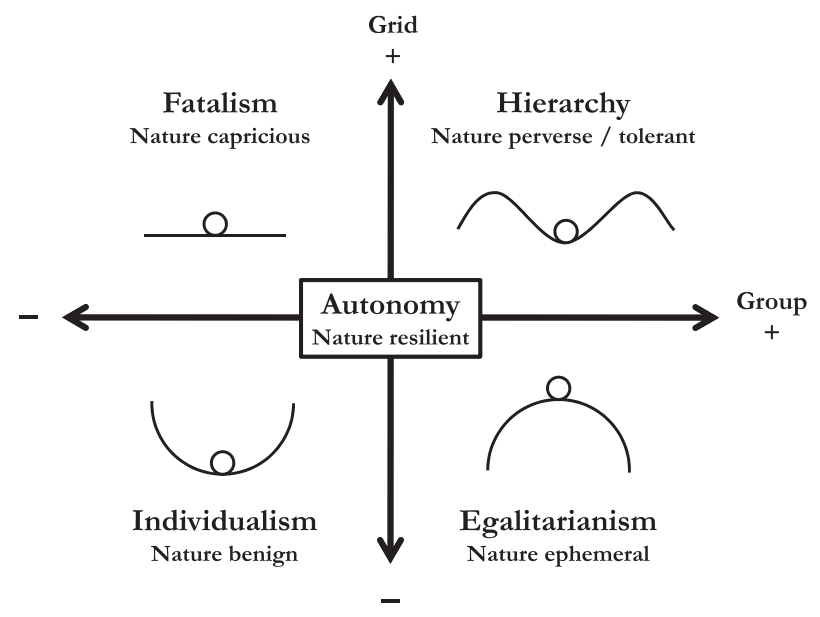

FIG. 1. The five ways of life and their associated myths of nature mapped onto the two dimensions of sociality (adapted from Douglas 1970; Thompson et al. 1990; Thompson and Rayner 1998).

Each of the four primary myths of nature is a partial representation of the reality of nature, yet to their associated ways of life they are perceived as self-evident truths. Those who view nature and the climate as perverse/ tolerant are congruent with the hierarchist way of life (Rayner 1991), believing climate change to be manageable within limits. They are therefore receptive to the idea of abrupt climate change, while seeking a scientific understanding of its characteristics so as to better inform that management. Characterized by the social contexts of strong social regulation and contact, hierarchists view risks as acceptable, so long as they are made by experts. When considering their preferences for mitigating climate change they are therefore likely to favor expert decision making and institutional or regulatory controls over greenhouse gas emissions (Thompson and Rayner 1998).

On the other hand, viewing climate as benign is congruent with the individualist way of life, believing it to be forgiving toward the exploitative activities of humanity. They are therefore relatively unreceptive to the idea of abrupt climate change, believing that anthropogenic perturbations of the climate system would never cause it to become unstable. Bound by both weak social regulation and contact, individualists see risks as an opportunity for economic gain and their outcomes as a personal responsibility. Their preferences for mitigating climate change therefore lie with technocentric, market-based approaches (Thompson and Rayner 1998).

In contrast, those viewing climate as ephemeral are congruent with the egalitarian way of life (Rayner 1991), believing it to be very unstable. They are therefore very receptive to the idea of abrupt climate change, believing 


\section{FATALISM}

- Climate is capricious

- Humans are fickle and untrustworthy

- Blame is attributed to fate

- Economic growth is acceptable, though it can only be acquired through chance

- Risk is unpredictable

- Outcomes are a function of chance: "why bother?"

\section{HIERARCHY}

- Climate is perverse/tolerant

- Humans are deeply flawed but can be redeemable by firm, nurturing and long-lived institutions

- Blame is attributed to deviants

- Economic growth is preferred, collective sacrifice will lead to group gain

- Risk is acceptable, so long as decisions are made by experts

- Outcomes can be managed to be sustainable with certified experts and statutory regulation

- Climate is ephemeral

- Humans are caring and sharing

- Blame is attributed to the system (some combination of hierarchism and individualism)

- Economic growth compromises equality

- Risk is catastrophe

- Outcomes require altruism and common effort in voluntary simplicity

\section{EGALITARIANISM}

FIG. 2. Cultural interpretation framework: the four primary ways of life and their preferences (derived from Thompson et al. 1990; O'Riordan and Jordan 1999; Ney and Thompson 2000; Thompson 2008).

that even the slightest perturbation might bring about a tipping point toward a far more inhospitable world. Seeing risks as imminent catastrophes, they view the technocentric ideals of individualists as the root cause of climate change, dismissing them as a threat rather than a solution. Instead, bound by weak social regulation but strong social contact, they advocate an ecocentric voluntary simplicity and common effort to alleviate climate change (Thompson and Rayner 1998).

Conversely, those who view the climate as capricious are congruent with the fatalist way of life, believing that abrupt climate changes are possible but inherently unpredictable. Viewing solutions as a function of chance, their preference is not to engage in mitigating climate change at all (Thompson and Rayner 1998).

\section{Methodology}

The two interpretations of cultural theory-stability and mobility - are each suited to distinct types of empirical testing (Marris et al. 1998). Proponents of stability argue that the use of quantitative psychometric questionnaires is a legitimate method for eliciting people's ways of life as they seek to organize their social experiences. On the other hand, proponents of mobility argue that such methods are prone to a cultural self-reporting bias and do not capture the relevant dimensions of dynamic social relations (Gross and Rayner 1985). Advocating the idea that ways of life can change in different social contexts, they propose that only qualitative methods can elicit the true depth of the ways of life. So as 
to take into consideration both interpretations, this research adopted a pragmatic (Cherryholmes 1992), multimethodological approach, combining both quantitative and qualitative methods in its design.

\section{a. Quantitative methods}

The quantitative component of the study was deployed as an Internet-based questionnaire using an online survey tool. Using a systematic self-selection sampling method, invitations to complete the questionnaire were dispatched via e-mail to students and staff at the University of East Anglia (UK), receiving 287 responses. The questionnaire comprised three sections: a psychometric instrument designed to elicit ways of life within the cultural theory grid-group typology; a series of questions designed to elicit perceptions of abrupt climate change; and a series of sociodemographic questions to allow for sample profiling (see Table 1).

\section{1) PSYCHOMETRIC INSTRUMENT}

Designed to elicit ways of life within the cultural theory grid-group typology, the psychometric instrument deployed a modified version of the statements developed by Karl Dake in his 1991 empirical attempt to reveal ways of life (Dake 1991). Four statements were selected for each way of life, where respondents were asked to reveal their level of agreement with the statements on a four-point Likert scale ranging from 1, "strongly agree," to 4 , "strongly disagree."

To attribute each respondents' way of life, four mean scores, one for each of the biases, was calculated in accordance with the method outlined by Marris et al. (1998). For a particular way of life to be attributed, one of these four mean scores was required to be below the mean for the sample and the other three above. Using this method $23 \%$ of the sample were attributed ways of life, comprising 47 egalitarians, 12 hierarchists, 6 individualists, and 2 fatalists. Of the remaining respondents, 3 were consistent with autonomy, having all four scores above the sample mean, and 217 were attributed mixed ways of life (with two or more scores below the sample mean).

To evaluate the reliability of this psychometric instrument, the internal consistency of the statements was determined using Cronbach's alpha. Using this test, Cronbach's alpha coefficients found to be greater than 0.6 were considered acceptable in accordance with Hair et al. (1998). The individualism and egalitarianism scales had coefficients of 0.64 and 0.68 , respectively, and were therefore found to be acceptable. The hierarchy and fatalism scales, however, were found to be 0.38 and 0.57 , respectively. This is not to say these scales were ineffective, however, as the test measured several dimensions of
TABLE 1. Sociodemographic profile of the 287 questionnaire respondents.

\begin{tabular}{|c|c|c|}
\hline $\begin{array}{c}\text { Sociodemographic } \\
\text { variable }\end{array}$ & $\begin{array}{c}\text { Sociodemographic } \\
\text { subvariable }\end{array}$ & $\begin{array}{c}\% \text { of } \\
\text { sample }\end{array}$ \\
\hline \multirow[t]{2}{*}{ Gender } & Female & 56.6 \\
\hline & Male & 43.4 \\
\hline \multirow[t]{4}{*}{ Age } & $18-22$ & 44.9 \\
\hline & $23-30$ & 27.9 \\
\hline & $31+$ & 26.5 \\
\hline & Decline response & 0.7 \\
\hline \multirow[t]{8}{*}{ Origin } & Africa & 1.7 \\
\hline & Asia & 1.4 \\
\hline & Australia & 1.0 \\
\hline & Europe (UK) & 80.5 \\
\hline & Europe & 10.8 \\
\hline & North America & 3.5 \\
\hline & South America & 0.7 \\
\hline & Decline response & 0.3 \\
\hline \multirow[t]{8}{*}{ Religious views } & Agnostic & 20.2 \\
\hline & Atheist & 32.1 \\
\hline & Buddhist & 1.7 \\
\hline & Christian & 26.8 \\
\hline & Jewish & 0.7 \\
\hline & Muslim & 0.7 \\
\hline & Other & 6.3 \\
\hline & Decline response & 11.5 \\
\hline \multirow[t]{6}{*}{ Political views } & Conservative & 11.1 \\
\hline & Green Party & 18.5 \\
\hline & Labour & 12.2 \\
\hline & Liberal Democrat & 18.1 \\
\hline & Other & 10.1 \\
\hline & Decline response & 30.0 \\
\hline
\end{tabular}

each way of life and as a result the coefficients may have been deflated.

\section{2) Questionnaire Design}

To elicit perceptions of abrupt climate change, a closed question structure was deployed in a "funnel" sequence, tackling broader themes early with later questions becoming more focused in a logical progression (Oppenheim 1992). The first theme provided context, examining concern about abrupt climate change as distinct to climate change in general. Here, respondents were asked to indicate their level of concern about each potential change on a four-point Likert scale ranging from 1, "very concerned," to 4, "very unconcerned." The second theme addressed perceptions of the likelihood of eight suggested abrupt climate changes, drawn from the policy-relevant "tipping elements" identified by Lenton et al. (2008) (see Table 2). Respondents were asked to indicate which of those changes they felt were likely to occur within the next 50 years. Following on from the likelihood of given abrupt climate changes, the third theme examined fears of those changes. Respondents were asked to indicate which of the changes they considered "dangerous," and which one in 
TABLE 2. The eight suggested abrupt climate changes and their main claimed consequence (based on Lenton et al. 2008).

\begin{tabular}{ll}
\hline \multicolumn{1}{c}{ Abrupt climate change } & \multicolumn{1}{c}{ Main claimed consequence } \\
\hline Decrease in Arctic ozone column depth & Increased UV at earth's surface \\
Decrease in areal extent of Arctic sea ice & Amplified global warming \\
Decrease in Atlantic thermohaline circulation overturning & Regional cooling \\
Increase in El Niño-Southern Oscillation amplitude & Drought in South East Asia and elsewhere \\
Decrease in volume of Siberian permafrost & Amplified global warming \\
Decrease in hydrate volume of marine methane hydrates & Amplified global warming \\
Decrease in ice volume of Greenland Ice Sheet & Sea level rise of $+2-7 \mathrm{~m}$ \\
Decrease in ice volume of West Antarctic Ice Sheet & Sea level rise of $+5 \mathrm{~m}$ \\
\hline
\end{tabular}

particular they felt was most dangerous. The fourth and final theme explored preferences for how to mitigate abrupt climate changes. This was operationalized by asking respondents to select which mitigation strategies they considered to be most appropriate for reducing the risks posed by abrupt climate change from a list of seven mitigation options.

\section{b. Qualitative methods}

The qualitative component of the study was developed as two separate focus group interviews as a follow-up to the questionnaire, 10 days after its completion. Using a purposive sampling method, invitations to attend the focus groups were dispatched to selected questionnaire respondents who had indicated they were available to take part. Fifteen participants were selected according to their ways of life as determined in the questionnaire, to obtain the greatest possible diversity of cultural representation.

\section{1) FOCUS GROUP DESIGN}

Designed to directly complement the questions in the questionnaire, the focus group setting enabled participants to reveal their perceptions in greater detail. Deployed in a funnel sequence, the procedure began with a broad introductory question regarding participants' concerns about climate change in general. This was followed by a transition question regarding concerns about abrupt climate change specifically. With the participants now engaged with the broad and narrowing focus of the study, the key questions were deployed. These focused on the perceived likelihood of abrupt climate changes occurring within the next 50 years and their beliefs about what might happen were any of them to occur. Perceptions of fear were then addressed by probing what participants considered to constitute danger and catastrophe. Following these key questions, the ending question addressed participant preferences in mitigating abrupt climate changes.

\section{2) Cultural interpretation}

Abridged transcripts of the focus groups were analyzed using the "framework analysis" procedure outlined by Krueger (1994). Individual questions and the sessions as a whole were critically examined for emerging themes and then coded into categories, into which related comments were categorized. Upon categorization, the comments were interpreted and contrasted using a custom-designed qualitative cultural theory framework (see Fig. 2). Constructed as a "quick reference" to the defining values and beliefs of each of the four primary ways of life, the framework facilitated an in-depth understanding of perceptions that the focus groups were designed to offer. These qualitative interpretations were then examined alongside the quantitative results of the questionnaire to determine the degree to which they complemented each others' findings and to evaluate the coherence of cultural theory in explaining perceptions in a multimethodological context.

\section{Results and observations}

\section{a. Concern about abrupt climate change as distinct to climate change in general}

In addressing concerns, the questionnaire revealed that the sample population was concerned about both climate change in general and abrupt climate change in particular. Mean Likert scores of 1.71 and 1.91 were calculated for each concern, respectively (where the scale ranged from 1 , very concerned, to 4 , very unconcerned), revealing a subtle lesser concern about abrupt climate change as distinct to climate change in general.

Within the sample population, mean scores of concern varied noticeably between each of the four ways of life, with those displaying an egalitarian bias consistently showing greater concerns than the others about both climate change in general and abrupt climate change in particular (see Fig. 3). Using a one-way multiple comparisons analysis of variance (ANOVA), these differences were found to be statistically significant for climate change in general $(F=5.237 ; \mathrm{df}=3,63 ; p<0.01)$ where a posthoc Scheffe comparison test revealed that the differences lay between egalitarians and fatalists; and very significant for abrupt climate change $(F=6.895 ; \mathrm{df}=3$, $63 ; p<0.0005)$ where the differences lay between egalitarians and individualists. 


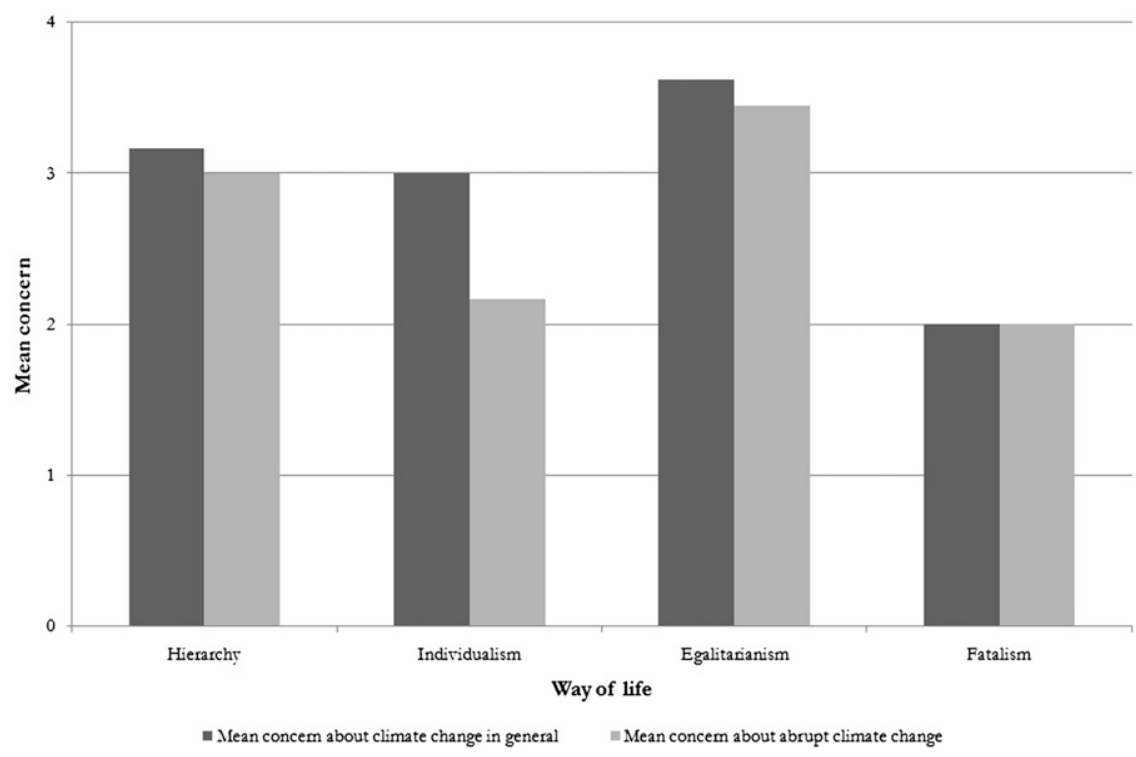

FIG. 3. Mean concern about abrupt climate change as distinct to climate change in general across ways of life (Likert scale ranging from 1, very unconcerned, to 4, very concerned).

Statistically significant, although weak, associations between concerns and ways of life were also found using a Pearson chi-square test of association and Cramer's V measure of strength, proving to be very significant between the two variables for climate change in general $(p<$ 0.001 ) and a significant association for abrupt climate change $(p<0.01)$. For climate change in general the association was revealed by crosstabulation adjusted residuals to be composed of an unconcerned attitude held by those displaying an individualist bias, a very unconcerned attitude held by those displaying a fatalist bias, and a very concerned attitude held by those displaying an egalitarian bias. Concurrently, egalitarians displayed a significant dissociation from the very unconcerned attitude. Those with a hierarchist bias displayed no significant associations with concern. For abrupt climate change the associations mirrored those of the former, with one additional finding. Here, those displaying an individualist bias displayed a significant dissociation with the very concerned attitude.

Providing a deeper understanding of the reasoning behind these perceptions, the qualitative focus groups revealed a number of emergent themes reproduced independently in each focus group. These themes were coded under the four categories of "evidence," "catastrophe," "helplessness," and "justice/equity."

The first theme-evidence-related to the idea that the scientific evidence of climate change, and in particular abrupt climate change, influenced their concerns. Much of the discourse here centered on the uncertainties of climate science and was framed by different participants as both a reason to be concerned and a reason not be concerned. Support for the former framing-concerncame from beliefs about the extent of what could potentially happen. For example, Participant 63 remarked "I think it's the unknown... we don't actually know the extent of what could happen." These comments came from participants who had shown at least some psychometrically attributed tendency toward egalitarianism and the belief of nature as ephemeral. Conversely, support for the framing of uncertain evidence as a reason not to be concerned came from beliefs about unpredictability. For example, Participant 69 remarked that "nobody really knows what's going to happen." This idea resonates with the belief of nature as capricious and of risks as unpredictable, values held by fatalists, including Participant 69 , who was revealed to display mixed ways of life with a tendency toward fatalism. This apparent lack of concern supports the significant findings of an association between fatalism and the "very unconcerned" attitude in the questionnaire.

The second theme-catastrophe-related to the idea that climate change, and in particular abrupt climate change, presents considerable danger to humanity. Discourses in this category were dominated by comments revealing beliefs of systems and nature as ephemeral and risks as catastrophic, values held by egalitarians. Indeed, all of the comments in this theme were made by those who had shown at least some tendency toward egalitarianism. For example, Participant 265 commented "for me, it's the capacity of rapid climate change to completely wreck civilisation as we know it." This high level of concern resonates well with the significant 
associations between the very concerned attitude of those who displayed an egalitarian bias and their dissociation with the very unconcerned attitude found in the questionnaire.

The third theme-helplessness-was linked to the idea that climate change, and in particular abrupt climate change, presents an insurmountable problem. Comments made within this theme were framed predominantly by opposing egalitarian and fatalist values. Egalitarian values returned to the theme of evidence and framed the idea of helplessness around the potential catastrophic consequences of abrupt climate change. These manifested in discussion as beliefs surrounding nature as vulnerable and risks as catastrophic, extending further support to the findings of the questionnaire where those displaying an egalitarian bias demonstrated heightened levels of concern. For example, Participant 220 described rapid climate changes as "... unstable or unpredictable to the extent that we have no way of mitigating or indeed adapting to it...." Beliefs about helplessness framed from a fatalistic perspective were revealed as low levels of concern owing to their values about the unpredictability of risks. Although supporting the fatalist findings about concern from the questionnaire, the focus groups revealed additional participants with fatalistic tendencies who had not been identified as having them through the psychometric questionnaire.

The fourth theme- justice/equity — was connected with the idea that levels of concern were influenced by perceptions of intergenerational and intragenerational justices and equities. To illustrate, Participant 220, who displayed an egalitarian bias, expressed concerns about the legacy the present generation would leave for their children. Indeed, the same participant places the blame for anthropogenic climate change on the global "north," an egalitarian idea implicitly synonymous with the blaming of "the system" and economic growth as the root of injustice and inequity. These further qualitative dimensions of egalitarian values strengthen support for the significant associations between the very concerned attitude of those who displayed an egalitarian bias and their dissociation with the very unconcerned attitude found in the questionnaire.

\section{b. The likelihood of abrupt climate changes}

In addressing perceptions of the likelihood of abrupt climate changes occurring, the questionnaire showed that the mean frequency of how many abrupt climate changes were considered likely to occur within the next 50 years varied noticeably between ways of life. Those displaying an egalitarian bias showed the highest mean frequency of changes they believed likely to occur, followed by those displaying biases of hierarchism, individualism, and lastly fatalism. These differences were statistically significant $(F=2.916$; df $=3,63 ; p<0.05)$, though associations between perceptions of likelihood and ways of life were found to be statistically insignificant.

A deeper understanding of the statistical insignificance between frequencies of likelihood and ways of life was unveiled in the qualitative focus groups data. Rather than beliefs about the stability of nature, participants' perceptions appeared to be largely governed by scientific knowledge and the media. Comments could therefore be coded into one category of "evidence" as the main reasoning behind perceptions of likelihood. There were, however, subtle references revealing beliefs about the stability of the natural world. For example, Participant 117, who displayed a hierarchist bias, commented on their mistrust of the media and its "emotional responses to [the likelihood of abrupt climate change]." This idea sits easily with the values of hierarchists regarding a placement of trust within long-lived institutions, such as science. Moreover, Participant 115 , who displayed an egalitarian bias, made reference to his/her beliefs of nature as ephemeral: "even if... something wiped out the entire population and we stop emitting any carbon I think sea ice is still doomed."

\section{c. Fears of abrupt climate change}

In addressing fears, the questionnaire revealed that the sample population considered the collapse of the Atlantic thermohaline circulation-which would result in regional cooling [see Lenton et al. (2008) for an authoritative description of this and the other possible abrupt climate changes referred to in this study] - to be the most dangerous, although least likely, possible abrupt climate change. Within the sample population, the mean frequency of abrupt climate changes considered dangerous varied noticeably between ways of life, with those displaying an egalitarian bias perceiving the largest number of abrupt changes to be dangerous (6.09) (see Fig. 4). These differences were statistically highly significant $(F=$ $6.119 ; \mathrm{df}=3,63 ; p<0.001)$ and lay between egalitarians and individualists.

Highly statistically significant and strong associations between fears and ways of life were also found $(p<$ 0.0005 ), composed of a number of associations across each of the ways of life. Those displaying a hierarchist bias showed an association with believing none of the abrupt climate changes to be dangerous, while showing dissociation with perceiving a large frequency to be dangerous. Similarly, those displaying individualist and fatalist biases showed associations with lower frequencies of changes considered to be dangerous. Those displaying an egalitarian bias, on the other hand, showed an 


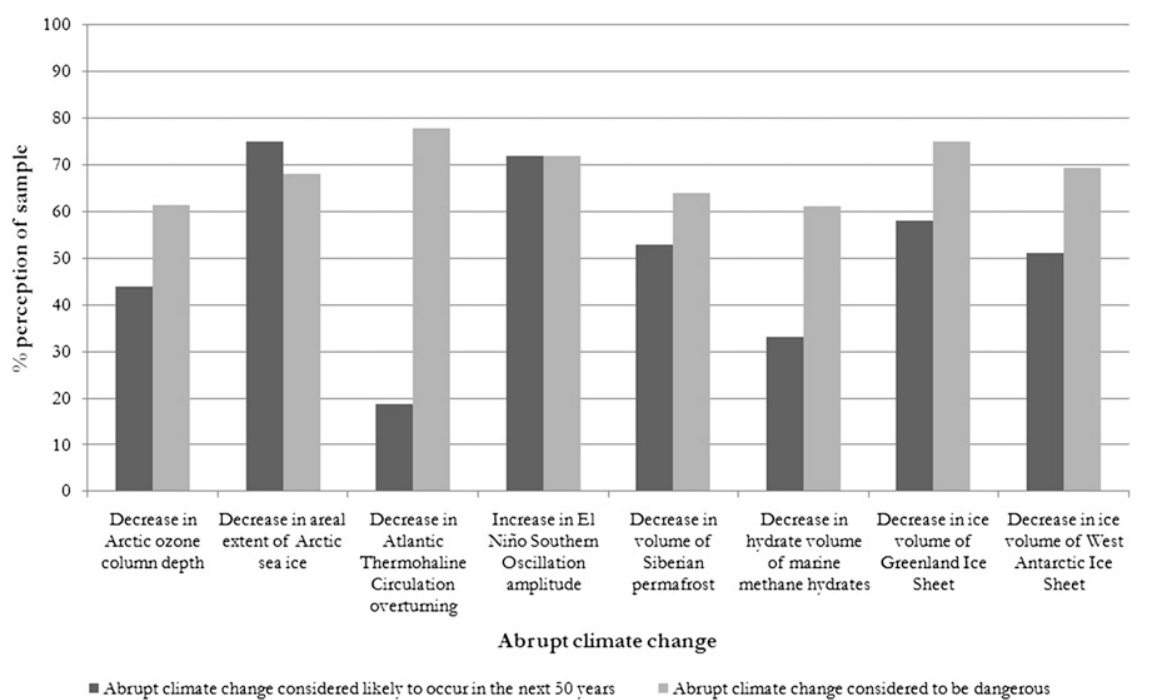

FIG. 4. Perceptions of the likelihood and level of danger posed by possible abrupt climate changes.

association with a large frequency of changes considered to be dangerous, while showing dissociation with perceiving lower frequencies.

The significance of the statistical associations identified between perceptions of danger and ways of life was reflected in the qualitative focus groups data and coded under the two categories of "societal" and "temporal" vulnerabilities.

The first theme-societal vulnerabilities-was connected to the idea that the construction of danger and fears thereof relate to people's perceived proximity to experiencing abrupt climate change. Comments within this theme comprised revealed beliefs suggesting the involvement of all the ways of life. The first idea focused upon the relative safety of developed countries, suggesting the placement of faith in long-lived institutions and experts for protection. This line of thought was followed by Participant 18 , with a tendency toward hierarchism, who declared that "....in the UK or at least in western Europe and most parts of America there's not actually too much in the way of great danger... these are mostly insurance and economical issues rather than real threat to life." At the same time, comments were made about the comparably more dangerous situation for developing countries. For instance, Participant 206, who displayed an egalitarian bias, stated "...those low-lying states in the Caribbean and the Maldives, they're facing serious danger from sea level rise... they've got nowhere to go." This affinity for intragenerational equity sits easily with the beliefs of risk as catastrophe and a call for altruism and common effort to alleviate the danger, values held by egalitarians.
In contrast, one participant viewed danger not in the physical sense but in the threat to their lifestyle, an idea reminiscent of individualism even though this tendency was absent from the participant's psychometrically attributed way of life. Here, Participant 237 commented that their fear lay with being "... at some point forced to change our lifestyles... radically I think." Fatalist commentary was also voiced with regard to the perceptions of danger. Participant 69 made reference to the dangers of societal collapse and war, resonating with egalitarian values which, as with Participant 237, had also been absent from the participant's psychometrically attributed way of life. Accepting the dangers, however, Participant 69 commented also that "the rest of it's so uncontrollable anyway... there's nothing we can do about it."

The second theme-temporal vulnerabilities-was connected to idea that the construction of danger and fears thereof relate to people's perceived temporal proximity to experiencing abrupt climate change. Connections between the ways of life and perceptions of danger were more limited in this theme, with participants largely believing abrupt climate changes to be temporally distant. Comments made within this theme therefore appeared to contradict the previously ascertained beliefs about the likelihood of abrupt climate changes occurring in the next 50 years. For example, Participant 115 commented "...it's going to take a lot of time; it's not going to be catastrophic in my lifetime...." Furthermore, the notion of personal temporal proximity appeared to be an important factor in determining what participants considered to be catastrophic. Participant 69 , for example, commented that "[the Atlantic thermohaline circulation] 
is probably going to be more instant than the frozen methane so that's why I think that's more catastrophic."

\section{d. Preferences in mitigating abrupt climate change}

In addressing people's preferences for mitigating abrupt climate change, the questionnaire revealed a statistically highly significant, though relatively weak, association between preferences and ways of life $(p<0.001)$. This association was composed of an association between those displaying an individualist bias and the options of switching to nuclear energy and doing nothing. Those displaying a fatalist bias similarly advocated the option of doing nothing, while those displaying an egalitarian bias displayed the opposite tendencies, with dissociations between themselves and switching to nuclear energy and doing nothing. No significant association was found between those displaying a hierarchist bias and their preferences.

Providing a deeper understanding of the reasoning behind these preferences, the qualitative focus groups revealed a number of emergent themes reproduced independently in each focus group and were categorized and coded under "top-down," "bottom-up," and "diversity" approaches to governance.

The first theme-the top-down approach to governance-was the most widely advocated view held by participants. Here, comments focused upon advocating conventional, regulatory approaches to governance, views reminiscent of hierarchist values. However, such views were not exclusive to those who had demonstrated a tendency toward the hierarchism. For example, Participant 107, who displayed both egalitarian and individualist biases, stated that "individual people aren't. . . going to make a difference; it's got to come from governments to change it and make people change their behavior."

At the same time as these conventional ideas, however, radical variants of regulatory proposals were also present within this category. Two participants, 18 and 220, held strong beliefs about forcing low-carbon lifestyle changes on the public. Participant 220 stated "governments should be taking it more seriously and that to me should not only be encouraging individuals to adopt low carbon lifestyles but possibly enforcing it in some ways as well." This radical manifestation of hierarchical policies came from those participants adhering to the egalitarian way of life, attributing the blame of inaction to the system.

Even more radical proposals ensued as one participant with an egalitarian bias suggested a complete overhaul of the system. Advocating a shift in focus away from the accumulation of material wealth, Participant 115 claimed that such goals were damaging and "a big part of the problem." On the other hand, Participant 237 argued that "you can't force people to consume less. . . what I think is going to be necessary is to... develop ways for people to keep their lifestyle but with less consequences on the environment." This framing of risk as an opportunity for new innovation is indicative of individualist values, yet the participant had not shown this tendency under the psychometric instrument of the questionnaire.

Although no commentary was made to reinforce the contrasting views about pursuing nuclear energy found in the questionnaire, another key area of disagreement was detected which had not been found in the questionnaire: geoengineering. Generally, participants were against deploying geoengineering options, however, those who were in favor tended to display a psychometrically attributed hierarchist bias. In contrast, those participants displaying an egalitarian bias warned of the possible dangers of using geoengineering, advising extreme care over its use or denouncing it completely. Interestingly, no distinction was made by participants between different types of geoengineering - for example, carbon dioxide removal and solar radiation management. Geoengineering interventions were either endorsed or denounced as a collective. Indeed, as faith in conventional mitigation measures wavers amongst some opinion leaders and geoengineering interventions become increasingly considered as a serious policy option (e.g., Lenton and Vaughan 2009; Royal Society 2009), it is of great importance that "upstream" public engagement concerning the distinct geoengineering technology options occurs.

The second theme-the bottom-up approach to governance-was the least-advocated view held by participants. Focusing initially upon egalitarian values of altruism and common effort for governance, even here many of the comments were based upon a hybrid form of regulatory approaches to governance. For example, Participant 115 , one displaying both egalitarian and hierarchist tendencies, stated that "people have to really want to change before government will do it." While advocating this approach to governance another set of values were revealed, those of fatalism. Participant 69 , who displayed a psychometrically attributed fatalist bias, stated that despite advocating a bottom-up approach, "I'm kind of half: is there much of a point? Why don't we do our best to try and minimize our impact and just whatever happens, happens."

The third theme-the diversity approach to governance-although acknowledging the need for both top-down and bottom-up approaches, largely supported diversity within and between top-down approaches. For example, Participant 265, who displayed an egalitarian bias, stated: "we need a mixture of things, I think that we have the [renewable] technology. . . but I think that has to be coupled with energy reduction... we need carbon trading, we need taxing...." On the other hand, many 
participants agreed abrupt climate change to be beyond mitigation. Instead, as Participant 20 puts it: "in terms of rapid climate change I don't really think we can put something in place... because we don't know when or how it's going to manifest itself... it's more realistic to tackle climate change [in general]....'

\section{Discussion}

The results and observations of this study showed respondents and participants to be concerned about abrupt climate change, though to a lesser degree than climate change in general. Respondents and participants perceived many of the possible abrupt changes as dangerous, yet expressed seemingly contradictory perceptions as to their likelihood of occurrence. Some they described as catastrophic, while at the same time viewing such changes as a risk not to themselves, but to distant, developing countries. This perception is consistent with the findings of Lorenzoni and Pidgeon (2006), where they showed climate change in general to be perceived as an "unsituated" risk.

Within the sample populations, this study has shown that people's values and ontological beliefs influence their perceptions of abrupt climate change in a multitude of ways. Beliefs about the stability of climate, as represented by the myths of nature, were found to significantly influence perceptions. In agreement with the predictions of cultural theory (Thompson et al. 1990), the belief of nature as ephemeral adopted by egalitarians consistently revealed heightened sensitivity in concerns and perceptions of likelihood and danger. Concurrently, hierarchists and individualists with their beliefs of nature as perverse/ tolerant and benign, respectively, perceived abrupt climate change as less of a concern, less likely to occur and less dangerous. These findings support earlier research into the influence of ways of life upon perceptions of climate change in general (Leiserowitz 2005, 2006).

Perhaps most interestingly, beliefs in climate as capricious, habitually held by fatalists, were revealed as dominant in the focus groups despite very few participants having been psychometrically attributed such tendencies. Low levels of concern were reflected in the qualitative coded categories of catastrophe and helplessness. These beliefs were frequently framed in a context of alarmism, supporting the findings of O'Neill and Nicholson-Cole (2009) in that inducing fear will not engage people, but instead alienate them.

Values held by respondents and participants were found to significantly influence perceptions of abrupt climate change. In particular, as represented by the four primary ways of life, they were found to significantly influence mitigation preferences. The findings were largely in agreement with the cultural theory predictions of
Thompson and Rayner (1998). Although displaying no statistically significant associations, hierarchists qualitatively displayed an affinity for top-down, regulatory approaches to governance. Statistically, individualists strongly advocated both nuclear energy and doing nothing to mitigate abrupt climate change, yet neither of these findings was reflected in the focus group discussions.

In direct conflict with the preferences displayed by the individualists, egalitarians strongly denounced both nuclear energy and doing nothing to mitigate abrupt climate change. Qualitatively they showed an affinity for bottomup approaches and radical enforcement variants of topdown, regulatory approaches. These findings contrast with other research, which has shown egalitarians to show no affinity for bottom-up or environmental citizenship approaches (Stern et al. 1999). Many participants displaying tendencies toward multiple ways of life advocated numerous approaches under the diversity coding, though they remained largely attracted to top-down approaches.

Concurrently, many respondents and participants favored top-down, conventional regulatory or marketbased approaches irrespective of their apparent ways of life and corresponding expected policy preferences (Thompson and Rayner 1998). Rather, these findings are consistent with the concept of the hegemonic myth, in that the framing of climate change mitigation around such approaches has been "totalizing" to the point where alternate discourses are often denied (Rayner 1995).

As with beliefs about the stability of climate, preferences in mitigating abrupt climate change were also widely affected by fatalism, despite very few participants having been psychometrically attributed this tendency. Many participants believed abrupt climate change to be beyond mitigation. Indeed, participants perceived the phenomenon as capricious, despite holding quite different beliefs about climate change in general. This finding provides further evidence of an emerging fatalist discourse surrounding abrupt climate change, confirming existing concerns (e.g., Hulme 2009a).

Within the focus group discussions, several significant discourses emerged revealing values and beliefs. The egalitarian and fatalist ways of life found particular resonance with certain ways of framing abrupt climate change (Shanahan 2007) and an affinity for certain linguistic repertoires (Segnit and Ereaut 2007). In concordance with their heightened sensitivity to abrupt climate change, egalitarians engaged with the catastrophe and justice and equity frames, confirming the suggestions of Hulme (2009b). Similarly, they engaged with the linguistic repertoire of alarmism. Conversely, with their low sensitivity to abrupt climate change, fatalists engaged with the scientific uncertainty frame. Hence, it can be seen that the greater scientific uncertainty surrounding claims of abrupt 
climate change can be easily framed to cultivate the values and beliefs of fatalism.

Of the $23 \%$ of respondents attributed a single way of life (67), a large proportion were categorized as egalitarians (47), suggesting that the sample may have been biased. However, larger numbers of egalitarians have also been identified in other studies, suggesting this is inherent to the use of Dake's statements (Sjöberg 1997; Marris et al. 1998). Furthermore, with only $23 \%$ of the sample attributed to a single way of life, it might be construed that ways of life are not characteristics that can be captured by such questionnaires (Marris et al. 1998). Indeed, some argue that the low levels of cultural attribution reflect upon the weak explanatory power of cultural theory and thereby advocate a diminished role for it in determining perceptions (Boholm 1996).

The quantitative psychometric instrument of the questionnaire did not capture many of the values and beliefs which were revealed qualitatively in the focus groups. This is consistent with the suggestions of Sjöberg (2003), where significant quantitative findings were deemed not necessarily meaningful. Fatalist tendencies, for example, which had not been demonstrated in the questionnaire, were consistently revealed among participants in their discourses. This study therefore suggests that understanding the values and beliefs recognized by cultural theory may well be more appropriate when set in a qualitative context.

The psychometric instrument was administered a second time, immediately after the focus groups, to assess the stability of the ways of life. Many of the participants had, in fact, changed their ways of life since the first completion of the questionnaire, prior to the focus groups. This finding, in accordance with the latency of fatalistic worldviews as discussed earlier, supports the idea of mobility in that ways of life qualitatively change in different discursive contexts.

\section{Conclusions and implications}

These findings suggest a number of wider implications for the effective communication of scientific knowledge claims about abrupt climate change. The contrasting perceptions of abrupt climate change as revealed and reflected by individual values and beliefs add more understanding to the reasons for disagreements about climate change (cf. Hulme 2009b). In acknowledging these disagreements in unison with the notion of climate change as a wicked problem-one that defies rational and optimal solutions, and can be considered a symptom of yet more complex problems (Rittel and Webber 1973) —it becomes increasingly difficult to visualize the success of international negotiations in "solving" climate change.
Furthermore, in recognizing this diversity of perceptions we highlight the implications for deliberative democratic policy making. The cultural cognition of environmental risks and advocated policies means that such policies can be supported or opposed depending on how congenial they are to an individual's values and beliefs (Kahan et al. 2010). Policies should therefore reflect a "pluralistic advocacy" position, attempting to counteract cultural cognition biases by avoiding communications and communicators which incite cultural conflict between identifiable groups (D. Kahan 2011, unpublished manuscript).

However, a rather more specific narrative has emerged from within discussions about abrupt climate change: that of fatalism. This way of talking about climate change has implications both for the communication of scientific knowledge and for efforts in engaging people in seeking policy and/or behavior change. The discourses of fatalism revealed in this study were often deployed using an alarmism frame, with referrals to helplessness, societal collapse and catastrophe. Supporting the findings of O'Neill and Nicholson-Cole (2009) - fear does not engage people but is rather counterproductive-this suggests that accounts of abrupt climate change may be weakening people's inclination to seek and believe in solutions to climate change in general.

Further research should investigate the prevalence of fatalism in discourses surrounding abrupt climate change. This study has shown this disposition to be widespread in the population sample surveyed here and that it is entangled with other worldviews, reflected in discourses about the (in)opportunity for mitigating such change. Finding new ways of framing (abrupt) climate change which more positively engage different publics is therefore a high priority (Nisbet 2009; Wilkinson 2010).

\section{REFERENCES}

Boholm, A., 1996: Risk perception and social anthropology: Critique of cultural theory. Ethnos, 61, 64-84.

Broecker, W., 1987: Unpleasant surprises in the greenhouse? Nature, 328, 123-126.

Cherryholmes, C., 1992: Notes on pragmatism and scientific realism. Educ. Res., 21, 13-17.

Clark, P., N. Pisias, T. Stocker, and A. Weaver, 2002: The role of the thermohaline circulation in abrupt climate change. Nature, 415, 863-869.

Connor, S., cited 2009: Has the Arctic melt passed the point of no return? [Available online at http://www.independent.co.uk/ environment/climate-change/arctic-melt-passes-the-point-ofno-return-1128197.html.]

Dake, K., 1991: Orienting dispositions in the perception of risk: An analysis of contemporary worldviews and cultural biases. J. Cross Cult. Psychol., 22, 61-82.

Dansgaard, W., S. Johnsen, J. Moller, and C. Langway Jr., 1969: One thousand centuries of climatic record from Camp Century on the Greenland ice sheet. Science, 166, 377-381.

Douglas, M., 1970: Natural Symbols. Routledge, 177 pp. 
Gleick, J., 1988: Chaos: Making a New Science. Vintage, 352 pp.

Gross, J., and S. Rayner, 1985: Measuring Culture: A Paradigm for The Analysis of Social Organization. Columbia University Press, 146 pp.

Hair, J., Jr., R. Anderson, R. Tatham, and W. Black, 1998: Multivariate Data Analysis. Prentice Hall, 768 pp.

Hansen, J., cited 2005: Is there still time to avoid 'dangerous anthropogenic interference' with global climate? [Available online at http://www.columbia.edu/ jeh1/2005/Keeling_20051206.pdf.]

Holling, C., 1986: The resilience of terrestrial ecosystems: Local surprise and global change. Sustainable Development of the Biosphere, W. Clark and R. Munn, Eds., Cambridge University Press, 292-317.

Hulme, M., 2003: Abrupt climate change: Can society cope? Roy. Soc. London Trans., 361A, 2001-2021.

_ c cited 2009a: Chaotic world of climate truth. [Available online http://news.bbc.co.uk/1/hi/sci/tech/6115644.stm.]

_ 2009b: Why We Disagree About Climate Change: Understanding Controversy, Inaction, and Opportunity. Cambridge University Press, 432 pp.

Kahan, D., H. Jenkins-Smith, and D. Braman, 2010: Cultural cognition of scientific consensus. J. Risk Res., 14, 1-28.

Krueger, R., 1994: Focus Groups: A Practical Guide for Applied Research. Sage Publications, $255 \mathrm{pp}$.

Laitner, S., and G. Parker, 2006: EU warned of looming climate catastrophe. Financial Times, 20 October.

Leiserowitz, A., 2005: American risk perceptions: Is climate change dangerous? Risk Anal., 25, 1433-1442.

- 2006: Climate change risk perception and policy preferences: The role of affect, imagery and values. Climatic Change, 77, 45-72.

Lenton, T., and N. Vaughan, 2009: The radiative forcing potential of different climate geoengineering options. Atmos. Chem. Phys. Discuss., 9, 2559-2608.

—, H. Held, E. Kriegler, J. Hall, W. Lucht, S. Rahmstorf, and H. Schellnhuber, 2008: Tipping elements in the Earth's climate system. Proc. Natl. Acad. Sci. USA, 105, 1786-1793.

Lewin, R., 1999: Complexity: Life at the Edge of Chaos. Guernsey Press, 198 pp.

Lorenz, E., 1963: Deterministic nonperiodic flow. J. Atmos. Sci., 20, 130-141.

Lorenzoni, I., and N. Pidgeon, 2006: Public views on climate change: European and USA perspectives. Climatic Change, 77, 73-95.

Lowe, T., K. Brown, S. Dessai, M. de França Doria, K. Haynes, and K. Vincent, 2006: Does tomorrow ever come? Disaster narrative and public perceptions of climate change. Public Understanding Sci., 15, 435-457.

Marris, C., I. Langford, and T. O'Riordan, 1998: A quantitative test of the Cultural Theory of risk perceptions: Comparison with the psychometric paradigm. Risk Anal., 18, 635-647.

Moser, S., 2010: Communicating climate change: History, challenges, processes and future directions. WIREs Climate Change, 1, 31-53.

National Oceanic and Atmospheric Administration, cited 2009: Ice core drilling projects. [Available online at http://www.ncdc. noaa.gov/paleo/icecore/iicdc.html.]

Ney, S., and M. Thompson, 2000: Cultural discourses in the global climate change debate. Society, Behaviour and Climate Change Mitigation, E. Jochem et al., Eds., Springer, 65-92.

Nisbet, M., 2009: Communicating climate change: Why frames matter for public engagement. Environment, March-April, 15.
Nordhaus, W., 2007: Critical assumptions in the Stern Review on climate change. Science, 317, 201-202.

O'Neill, S., and S. Nicholson-Cole, 2009: Fear won't do it: Promoting positive engagement with climate change through imagery and icons. Sci. Commun., 30, 355-379.

O'Riordan, T., and A. Jordan, 1999: Institutions, climate change and cultural theory: Towards a common analytical framework. Global Environ. Change, 9, 81-93.

Oppenheim, A., 1992: Questionnaire Design, Interviewing and Attitude Measurement. Pinter Publishers, 290 pp.

Phillips, M., cited 2009: The inescapable has been seriously underestimated. [Available online at http://www.spectator.co.uk/ melaniephillips/3436241/the-inescapable-apocalypse-has-beenseriously-underestimated.thtml.]

Rayner, S., 1991: A cultural perspective on the structure and implementation of global environmental agreements. Eval. Rev., 15, 75-102.

_ 1992: Cultural theory and risk analysis. Social Theories of Risk, S. Krimsky and D. Golding, Eds., Greenwood Press, 83-115.

_ 1995: Governance and the global commons. Global Governance: Ethics and Economics of the World Order, M. Desai and P. Redfern, Eds., Pinter, 60-93.

Risbey, J., 2008: The new climate discourse: Alarmist or alarming? Global Environ. Change, 18, 26-37.

Rittel, H., and M. Webber, 1973: Dilemmas in a general theory of planning. Policy Sci., 4, 155-169.

Royal Society, cited 2009: Geoengineering the climate: Science, governance and uncertainty. [Available online at http:// royalsociety.org/Geoengineering-the-climate/.]

Russill, C., and Z. Nyssa, 2009: The tipping point trend in climate change communication. Global Environ. Change, 19, 336-344.

Segnit, N., and G. Ereaut, 2007: Warm words II: How the climate story is evolving. Institute for Public Policy Research/Energy Savings Trust Rep., $51 \mathrm{pp}$.

Shanahan, M., 2007: Talking about a revolution: Climate change and the media. International Institute for Environment and Development Rep., 4 pp.

Sjöberg, L., 1997: Explaining risk perception: An empirical and quantitative evaluation of cultural theory. Risk Decis. Policy, 2, 113-130.

_ 2003: Distal factors in risk perception. J. Risk Res., 6, 187-212.

Skrimshire, S. E., 2010: Future Ethics: Climate Change and Apocalyptic Imagination. Continuum Press, $312 \mathrm{pp}$.

Spash, C., 2007: The economics of climate change impacts a la Stern: Novel and nuanced or rhetorically restricted? Ecol. Econ., 63, 706-713.

Stern, P., T. Dietz, T. Abel, G. Guagnano, and L. Kalof, 1999: A value-belief-norm theory of support for social movements: The case of environmentalism. Hum. Ecol. Rev., 6, 81-97.

Thompson, M., 2008: Organising and Disorganising: A Dynamic and Non-Linear Theory of Institutional Emergence and Its Implications. Triarchy Press, 160 pp.

—_, and S. Rayner, 1998: Cultural discourses. Human Choice and Climate Change, Vol. I, The Societal Framework, S. Rayner and E. Malone, Eds., Battelle Press, 265-344.

_ , R. Ellis, and A. Wildavsky, 1990: Cultural Theory. Westview Press, $296 \mathrm{pp}$.

Wilkinson, K., 2010: Climate's salvation: Why and how American evangelicals are engaging with climate change? Environment, March-April, 48-57. 